\title{
Empirical Research on the Modern Literary Trend under the Background of Internet
}

\author{
Yan Li \\ Linyi University Feixian Campus, \\ Linyi,Shandong,273400 China
}

\begin{abstract}
In this paper, we conduct research on the modern literary trend under the background of the Internet. The modern network literature has become a proper noun with special connotation, in the development of network technology, driven by the modern literature already contains the traditional literature and network literature two main content. Network literature is developed on the basis of the traditional literature, with a variety of unique content, but also an important part of modern literature. Modern network literature has been general recognition, at present the study of the network literature qualities is also very hot. The most important feature of network literature as should be the innovation in the form of text. Therefore, our research starts from the analysis of the corresponding concerns and challenges to achieve for the better output.
\end{abstract}

\section{Keywords-Modern Literary, Trend, Background, Internet, Empirical Research.}

\section{Introduction}

Media is the literary production, transmission, exchange and the consumption of the link which is an indispensable tool in the whole process of literary production and carrier. Media to a certain extent, decides the thinking mode of literary production, dissemination way and accept the way. Looking back on history, human society has come a spoken culture, the word culture stage, is now entered the era of media culture. From the point of view of the media and cultural era people by word of mouth words spoken as the main medium of communication, text culture era in a variety of printed material is the main carrier of the media that have taken place in today's media culture transformation of the visualization. The whole process of literary creation is actually a complete process of mental activity. Emotion is the response to the objective reality of a kind of special form is whether objective things meet people's needs and the attitude and the primary experience [1-3].

Literary creation can be accumulated as the representation and is used to design the material, then with the combination of emotion, of course, also can play the same role in literary creation. The stored in the memory of the emotion, but as the memory and retrieval is bound to be reflected in the creative imagination of the author. New media writers and the readers are the main body to become a reality. Literature of the author and audience, the scale of production and consumption of literature and the way has changed. New media to make the reader into the creative process of freedom, equality, direct to make revisions, text and quickly feedback to the creator as new media presents a multidimensional nature in literary production and the characteristics of subjectification, conducive to the communion and innovation of various kinds of art forms. The change of the media, to traditional literature brings great impact at the same time also provide a new opportunity and growing point for literary creation. 
The spread of Internet with its information two-way interactivity, multimedia, public participation of the extensive rewriting the history of mass media, known as the traditional newspapers, radio and television these mass media after the "fourth media" network literature is based on Internet network infinite connected to grow, although it is first produced and published, spread on the Internet, but it is not only exist in the network. Network literature newspapers reprinted or after printing to the paper books, is still the network literature, reading and reading on paper on the screen are all the same. And, of course, readers' feeling and the experience is certainly not the same. After we read on a computer, we can direct feedback information through the network, if like this novel, the author has proposed can be mentioned and seen by the authors directly on the net, and paper books is hard to do so quick response. Due to primary network changes reflect human nature way of information production and the dissemination, and as in turn, changed the human production, life style, therefore it will drive the changes of the society as a whole that bring human beings into the highly information-based society. Network literature, with its unique form, direct or indirect way, reflects the profound changes of our human groups are the life and we are in the social relationships, communication form or the emotional changes into a kind of "network" while the network literature has its own characteristics. In the figure one, we show the keywords of the modern literary [4].

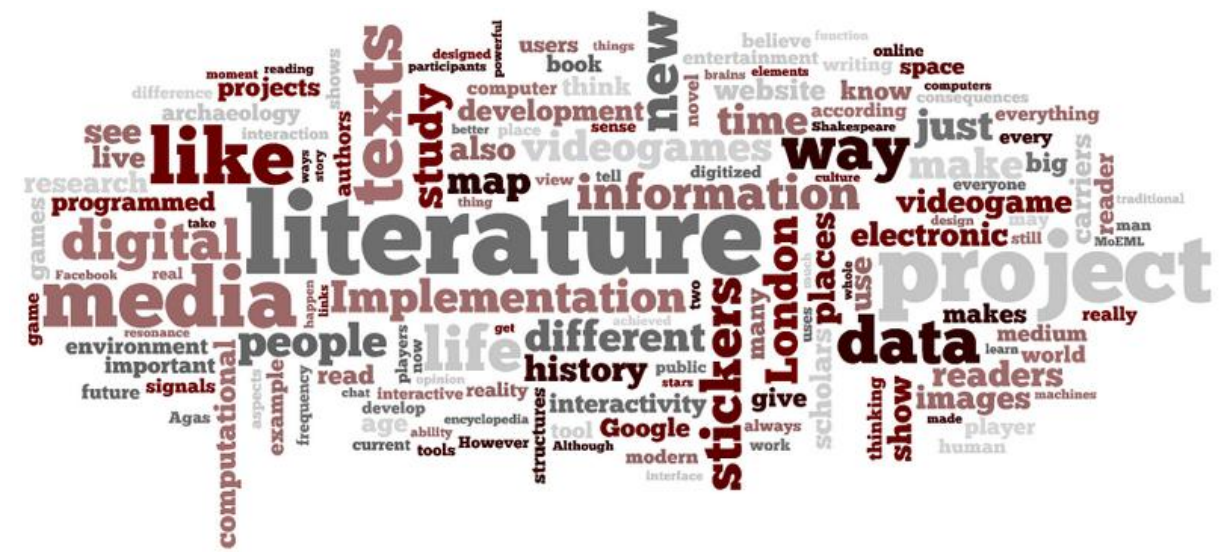

Figure 1. The Keywords of the Modern Literary

In this paper, we conduct research on the modern literary trend under the background of Internet. Real high-quality goods online literature creation, should have ability to text ideological implication of moderate mining, on stylistic structure or writing skills should also be given some attention, at the same time must be to pour into the sincere sentiment, and fused cast a very pious attitude of writing, the only way, network literature creation to complete and sincere individual emotion of people as can smooth and natural to express the idea that free will, just also can have its unique existence value. In the later parts, we will describe our ideas and perspectives in detail.

\section{The Proposed Methodology and Perspective}

The Principles of the Literary Creation. Objective reality is the source of emotion. Any emotion is caused by the objective reality. According to the different features of objective things and the existing relationship between people and things, people hold different attitude towards to these things as has a different experience. Emotion is the people to the real world, therefore, reflect a kind of special form, left the specific objective things, the human emotion can produce. Emotion is not for no reason at all. Emotion is the most complicated aspect of people's behavior, as well as the most important aspect of human life. Literary creation 
subject in the state of fans crazy refers to: "the creation subject in literary creation activity of aesthetic emotion, sometimes with very strong tension and general excitement of the emotional experience. This kind of emotional experience will change the whole life of the body, making the internal organs of the creation subject to change, appear not homemade state thus reveal, the performance on the facial expression, body expressions and sound expression".

In this definition, there are two things as worth our attention: one is the creation subject fans crazy state in general literature creation activities, including literary conception and literary convey phase; Second, the fans crazy state is a state of uncontrolled creation subject, the "control" should include two aspects of inner psychological and external behavior and therefore, the "literary creation subject in the fan crazy state" of the narrow understanding [4-6].

Fans crazy state of creation subject, the nature of "forgetting" and the scientific research work of ecstasy is also different, the former is under intense emotional experience of "I", the latter due to pay attention to the objective and rational analysis, trying to eliminate subjective emotional involvement, its "forgetting" mainly refers to forget all about eating and sleeping, tireless these aspects. As for some people equate the creation subject fans crazy with confusion mental illness and intoxication is absurd.

Ecological literature creation in the new period, it is to point to in the new period since the Chinese writer with ecological intention or inclusion of the ecological consciousness of literary creation, it originated in the 1980s, 90s and developing rapidly in the new century, the boom period. So far, but to say this important literature ideological trend and creation phenomenon did not get enough attention and full of the mainstream research evaluation. In the new era ecological literary creation to give an outline to comb and analyze that aims to pay more attention to a broader and deeper discussion.
The Internet and Literary Creation. The Internet from the perspective of basic literary creation, publishing and media, changed the way the survival of traditional literature, and with its highly free, non-utilitarian and the folklore characteristics, break through the criterion of the value of traditional literature and aesthetic standard, to make up for the traditional concept of literary subversion. But this actually implies the new opportunities of literature. If after a century of film and television art media advantage makes literature gradually lost in the leading position of human art, then, in the face of the tremendous subsistence pressure of literary image era, it may be on the Internet to obtain the survival and development opportunities [7].

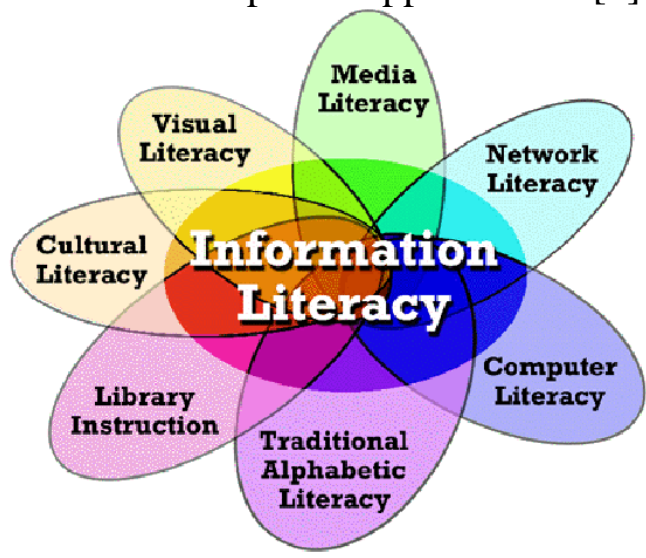

Figure 2. The Demonstration of the Information Literacy

Network literature theory researchers want to determine the meaning of outlines the concept of the network literature, but so far, not for its accurate definition, in most cases referred to the concept of the network literature, which content is not only in practice to answer the network literature. For what is the network literature, relevant personnel often have no way to list or outline main features. In this case, we can see how the network literature theory positioning and research is very complicated.

Literary form, this is the most essential features network literature text form. In the form of carrier network for transmission and dissemination is also the most important difference between network literature and 
traditional literature and one of the most simple standard, traditional literature is in the text form paper such as book or newspaper carrier medium for the spread of a form of literary texts, in the form, the traditional literature can be considered to be perceived, can touch in the literature. But, after the rise in the network literature, in the form of the "book" for the literary tradition is broken, a growing number of online literature form, take the network as primary carrier for transmission, in the dissemination of the convenient, fast, literature is more dynamic, traditional black and white of the revolutionary literature was formally beyond, become the colorful, bizarre, have the dreamland of the photoelectric effect. New carrier and transmission of the network literature form in a new era of the literature development which is the most typical features of contemporary literary era [8].

- The rapidity of the creative process, and interactivity. Network literature is not only the single creator express feelings of the carrier, due to the openness of the Internet, often the completion of a work depends on everyone's mutual discussion and the participation. This is a blend of a variety of style the structure new people the ridiculous. Here, there is no clear line between the writer and the reader, work is the crystallization of the collective wisdom interaction.

- The creation subject of civilian and liberalization in front of the network literature has stripped the sacred veil, completely to the public, published works is no longer a writer or professional literati privilege, as more accurately, a writer as a status symbol in the cyberspace has lost its meaning, writer's identity, status, honor and cultural capital, and so on are unable to continue in this unique space and status.

- The diversification of the network literature form and technique. Network literature due to the support of computer, network technology, overcome the oneness form, to achieve the effect of pictures, words and music union, show the dynamic characteristics of the static text. Network literature is known as the "fast food" literature, because it's fast, transmission is fast, absorb quickly, and determines that based on simple and easy solution.

As is known to all, both traditional literature and network literature that is the expression form of language, is a lyric expresses a kind of art form, embodies the author highly personalized thinking. Art is also the author thought expressed in language form to show the readers a kind of art, since the time development, the development of the language in literature in more and more vital. Network literature become the darling of the times as contribution to the literature mainly displays on the absorption of language forms, and clever apply. In modern life, people's language is largely affected by the network, many everyday language reflected in the network, the network language also appear more frequently.

The Features Modern Literature. Throughout the development of the development of literary history, literary theory and the development of literary translation, we can see, language is not only an important symbol of the development, or representation is the key factor restricting the development, that also can saying is the deep reason of these developments.

Ancient literature and modern literature, though both belong to the Chinese literature, but in fact are two different types of literature, ancient literature can be said to be the ancient Chinese literature, ancient resistance, its ancient and self-sufficient system of ancient Chinese have a deep relationship; Modern literature is the modern Chinese literature, has the modernity, the modernity and the modern Chinese system of modernity have the deep relationship. Forms of the modern Chinese language is Chinese, but it has essential difference with ancient as spoken Chinese, on the one hand, it absorbs the ancient 
Chinese language vocabulary, but more importantly, a large number of absorbing western words especially western ideology and culture, science and technology, so to make up a vocabulary, grammar, word and expression was different in China's ancient, it is also different from western very complete language system. In the modern transformation of Chinese literature and literary theory of the process, the translator plays a very important role. Since modern Chinese comprehensive learning western, in learning, physical form can be copied, learning directly, but need to be translated, ideology and culture things need to become Chinese form can be accepted by Chinese people.

Theory and theory of the western various ideas are being introduced and translated into Chinese, which related to language and language study profound influence on Chinese literature basically has the following four aspects. (1) The big difference is that the modern linguistics and the traditional linguistics, modern linguistics is no longer just focus on language form, such as words, grammar, pronunciation, vocabulary, etc., and at the same time also pays attention to the relationship between language and reality, pay close attention to language and logic. (2) The philosophy of the language, or very much concerned with the problem of language philosophy. It's a combination, confused on the name is very complex, some call it "the philosophy of language", some call it "linguistic philosophy", its content can include almost all academic fields, and there are a lot of interdisciplinarity. (3) These theories or derived from the philosophy, or under the influence of philosophy, while others come from literary criticism practice summary ascension, on the issue of language, their common characteristic is the emphasis on the importance of language that emphasize the semantic analysis. (4) Keyword research and issues of the past research or research one of the biggest differences is that it examines the occurrence and the evolution of the concept and the evolution of development of research thought, from the perspective of the concept and connotation of the research questions and topics.

\section{Conclusion}

In this paper, we conduct research on the modern literary trend under the background of the Internet. When the computer network rises from the horizon of literature, it by its fast information processing, free virtual space soon attracted the attention of the literature that was born a people both familiar and unfamiliar network era, the most characteristic of the era of new literature form the network literature. "Network literature" is a difficult to accurately define the concept of as perhaps there has been much debate in today it needs to be further theoretical research. However, the network literature there has been a development of this phenomenon in fact. Literature in the cyberspace and become an active molecules, it is indisputable fact. In the future, we will combine more related research to optimize the current proposed result.

\section{References}

[1] Love, Karen Gail. Recognition and despair: Mark Twain's The personal recollections of Joan of Arc as a modern literary allegory in the American tradition. Diss. 2013.

[2] Jiang, Jing. "From the Technique for Creating Humans to the Art of Reprogramming Hearts: Scientists, Writers, and the Genesis of China's Modern Literary Vision." Cultural Critique 80.1 (2012): 131-149.

[3] Lichtenstein, Nina B. "Sephardism: Spanish Jewish History and the Modern Literary Imagination ed. by Yael Halevi-Wise (review)." Journal of Jewish Identities 6.2 (2013): 100-102.

[4] Armstrong, Paul. "Monopolizing the Master: Henry James and the Politics of Modern 
Literary Scholarship by Michael Anesko

(review)." Common Knowledge 19.3 (2013): 563-564.

[5] Lin, Carlos Yu-Kai. "The Rise of Xiaoshuo as a Literary Concept: Lu Xun and the Question of "Fiction" in Chinese Literature." Frontiers of Literary Studies in China 8.4 (2014): 631-651.

[6] Juvan, Marko. "Doing literature without thinking: paralogical devices and the literary field." Canadian Review of Comparative
Literature/Revue Canadienne de Littérature Comparée 41.1 (2014): 54-71.

[7] Verma, Raj Gaurav. "Locating Reader Response Theory in Jauss's Literary History as a Challenge to Literary Theory." Language in India 13.5 (2013).

[8] Sharma, Sunil. "Redrawing the Boundaries of'Ajam in Early Modern Persian Literary Histories." Iran Facing Others. Palgrave Macmillan US, 2012. 51-64. 